\title{
INVESTIGATING SOIL EROSION DUE TO DEFECTIVE SEWER
}

S M Nazmuz Sakib

Gradaute, School of Business And Trade, Switzerland

Student, Dhaka International University

Student, Dhaka School of Economics

\begin{abstract}
Cases of road cave-ins have been reportedly increasing globally and reports have associated this phenomenon to underground soil erosion due to defective sewer pipes. As the sewer pipes age, they may develop some defects which may lead to cracks and crevices that will lead to infiltration of the soils surrounding the pipe into the pipe, leading to the formation of cavities around the pipe. Therefore, this study investigated the factors behind the causes of underground soil erosion due to defective sewer pipes and proffered solutions for combating underground soil erosion due to defective sewer pipes. The study objective included; (a) establishing how the soil particle sizes affect the internal soil erosion due to defective sewer pipes, (b) determination of the effect of defect sizes on the internal soil erosion due to defective sewer pipes, (c) establishing the effect of the embedment material used on the internal soil erosion due to defective sewer pipes, (d) investigation of the type of soil erosion mechanism in the presence of a buried sewer pipe defect caused by the groundwater infiltration process. The methodology of the study involved reviewing and analyzing secondary qualitative and quantitative data. The findings established that the defect size of the pipe, the type and characteristics of the soil and the type of embedment materials used affected erosion of soil around a defective sewer pipe.
\end{abstract}

Keywords: Erosion; Defective Sewer; Investigating soil; Soil Erosion; Soil Science

\author{
LIST OF ABBREVIATIONS \\ PSD Particle- Size Distribution \\ PIV Particle Image Velocimetry \\ SDA Secondary Data Analysis \\ FDC Four-Dimension Criteria
}




\subsection{INTRODUCTION}

\subsection{BACKGROUND REVIEW}

Incidents of sinkhole accidents resulting from underground soil erosion caused by defective sewer pipes are increasingly being reported across the globe. The resultant sinkhole accidents have been quoted to cause massive economic losses and threaten human life. For example, on 15th February 2018, a giant sinkhole formed in Rome, Italy, resulted in massive damages, leading to the evacuation of large populations into safety (Yokota et al., 2017). Another report by Yokota et al. (2017) revealed that between 3000-4000 road subsidence accidents attributed to soil erosion due to defective underground sewer pipes occur in Japan. Cases of sinkholes have also been reported in other places in the world.

Sinkhole and related underground erosions are a condition that occurs for an extended period. Sinkholes occurrence are attributed to several factors, including but not limited to aging of sewer pipes, lack or improper maintenance, and natural causes (Karpf \& Krebs 2011). The cracks, fractures, and openings of the underground sewer pipes due to deterioration over time allow the soil around the pipes to infiltrate the pipes spontaneously during infiltration of the groundwater in the defective pipes together with the immediate sewer exfiltration process (Karpf \& Krebs 2011). Over time, a continuous cycle of this process over a period of time causes a void to build up around the pipe that proceeds towards the ground surface, eventually creating a sinkhole (Tang, Zhu David \& Chan Dave, 2017). An illustration of a sinkhole formation due to groundwater erosion due to defective sewer pipes is shown in figure 1.

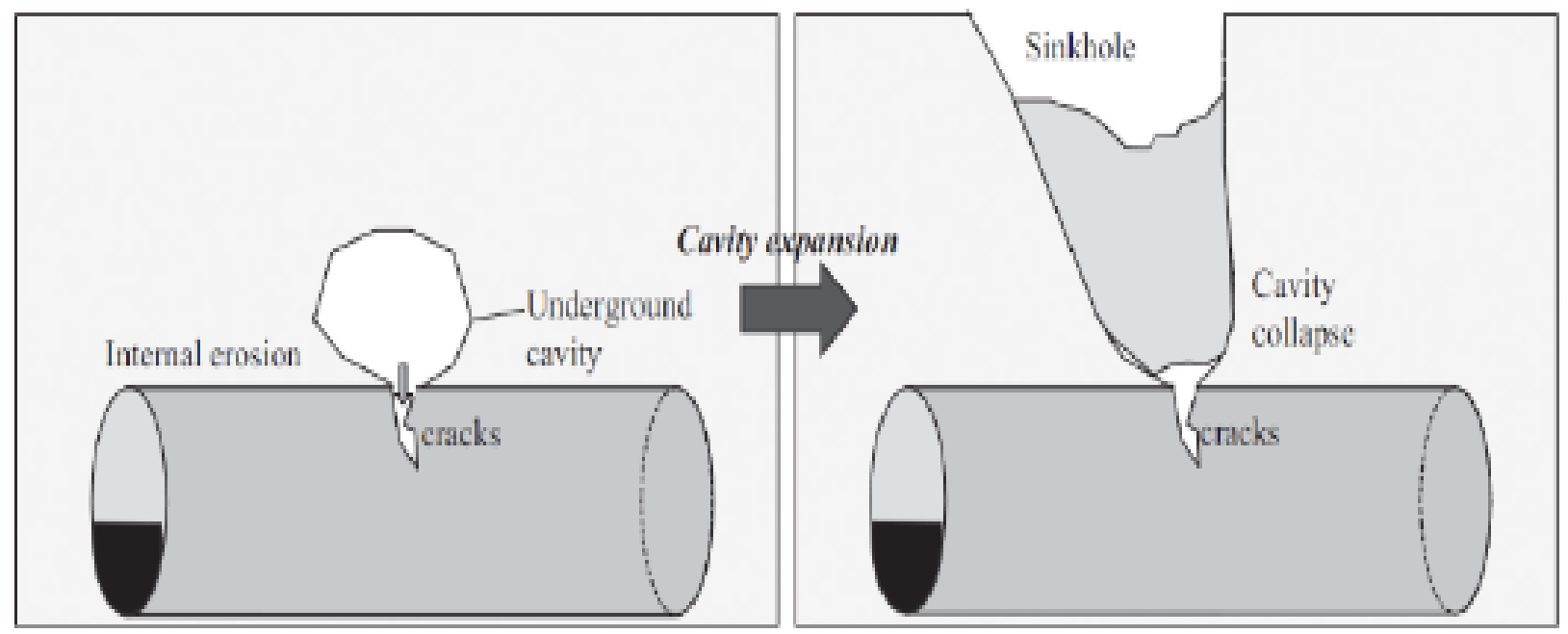

\section{FIGURE 1.1. A SINKHOLE AND UNDERGROUND SOUL EROSION DUE TO A DEFECTIVE SEWER PIPE.}

Obtained from Karoui et al. (2018).

The said underground erosion occurs when faulty sewer pipes allow inlets of water and soil into the faulty pipes via the defects. There are many factors in play regarding the causation of underground soil erosion in the vicinity of defective sewer pipes. According to Karoui et al. 
(2018), leak size is one of the most significant factors that affect the state of internal soil erosion around faulty sewer pipes. Therefore, the present research investigated the relationship between defective sewer pipes and underground soil erosion. It explored the impacts of leak width, soil particulate sizes, and embedment material on internal soil erosion. The ultimate goal was to determine factors that trigger underground soil erosion due to defective sewer pipes and utilize the findings in improving public safety.

\subsection{PROBLEM STATEMENT}

A comprehensive review of secondary data revealed a massive gap in the information available to address issues of underground soil erosion as a result of defective buried sewer pipes. First, there is limited knowledge on soil erosion mechanisms influencing underground soil erosion due to faulty sewer pipes. Guo and Zhu (2017) argued a knowledge niche about soil erosion mechanism and the critical parameters affecting the magnitude of soil eroded around the buried defective sewer pipes. Thus, a further investigation into these mechanisms is paramount towards mitigating the creation of sinkholes, particularly along the highways. Another vital subject is internal soil instability which is a significant factor that leads to the formation of sinkholes due to internal soil erosion. Several surveys on the internal stability of soils have been conducted for the past four decades. The studies have put forward varied geometric criteria for assessing the internal stability of the soil basing on the particle-size distribution (PSD) of particular soils (Chang \& Zhang 2013). However, the proposed geometric criteria are yet to provide a means of assessing the susceptibility of the soil around underground sewer pipes to erode upon breakage of the pipes (Chang \& Zhang 2013). Therefore, the findings of the studies were crucial in providing a basis for researchers to establish the best geometric criterion for assessing soil susceptibility to erosion within the vicinity of defective sewer pipes.

Furthermore, an empirical study established that many cases of ground subsidence are caused by groundwater due to defective sewer pipe leakage. A survey conducted in Seoul, South Korea, demonstrated that the leading causes of underground soil erosion are defective sewer and water pipes and excavation activities (Indiketiya, Jegatheesan \& Rajeev, 2017). However, a more significant percentage of this underground subsidence in Seoul is caused by defective sewer pipes than excavation works, representing $85 \%$ and 14\%, respectively (Jo, Cho \% Jang, 2016). For example, on a construction site at Yongsan Station, Seoul, South Korea, a sudden ground sinking caused by loss of soil particles and groundwater leakage from a defect in an excavation wall caused two pedestrians to fall into the sinkhole (Jo, Cho \% Jang, 2016). Therefore, this research was prudent to obtain information vital to preventing such a disaster that threatens public safety. Also, even though groundwater problems cause many cases of internal erosion, there is still a gap in understanding the mechanism of underground erosion due to groundwater. Therefore, this study was necessary to exploit the mechanisms of underground erosion due to faulty sewer pipes and improve public safety. 


\subsection{STUDY OBJECTIVES}

\subsubsection{AIM OF THE STUDY.}

The research aimed to evaluate the internal soil erosion due to defective sewer pipes. Utterly, the research findings aimed at increasing public safety by minimization of the consequences of internal soil erosion because of defective sewer pipes.

\subsubsection{SPECIFIC STUDY OBJECTIVES}

1. To establish how the soil particle sizes affect the internal soil erosion due to defective sewer pipes.

2. To determine the effect of defect sizes on the internal soil erosion due to defective sewer pipes.

3. To establish the effect of the embedment material used on the internal soil erosion due to defective sewer pipes.

4. To investigate the type of soil erosion mechanism in the presence of a buried sewer pipe defect caused by the groundwater infiltration process.

\subsection{RESEARCH QUESTIONS}

1. How does the soil particle sizes affect the internal soil erosion due to defective sewer pipes?

2. What is the effect of defect sizes on the internal soil erosion due to defective sewer pipes?

3. What are the effects of the embedment material used on the internal soil erosion due to the defective sewer pipes?

4. What are some of the soil erosion mechanisms occurring in an underground defective sewer pipe due to the groundwater and soil infiltration through the defective sewer pipe? 


\subsection{LITERATURE REVIEW}

\subsection{INTRODUCTION}

In this chapter, several secondary literature pieces were reviewed to establish the association between internal soil erosion and defective sewer pipes - the chapter began by illustrating incidents where soil erosion due to defective sewer pipes has occurred before. Further, the chapter reviewed literature factors contributing to the formation of defective sewer pipes and probable outcomes of soil erosion due to defective pipes. Also, the chapter presented issues to do with embedment materials, touching on factors such as type of bedding, soil properties, soil type, particle-size distribution, and initial density and relative compaction. Finally, the study reviewed the literature on sewer pipes defect size, highlighting factors such as granular flow through an opening and sewer pipe defect size measurement using PIV.

\subsection{INCIDENTS WHERE SOIL EROSION DUE TO DEFECTIVE SEWER PIPES HAS OCCURRED}

Detailed empirical evidence shows soil erosion events due to defective sewer pipes distributed in different parts. Research has shown that whenever sinkholes occur due to underground soil erosion due to defective underground sewer pipes, emergency efforts often focus on ensuring public safety and traffic flow instead of looking into the cause of the sinkholes. A case study by Hadjmeliani (2015) indicated that a sudden collapse that formed a large hole was observed on Tripoli's major roads. A failure analysis study carried out aftermath by Hadjmeliani (2015) established that the sinkhole was caused by the interior pipe that had suffered degradation, which leads to damages on the pipe wall, allowing fluid leaks, formation of cavities in the soil around the pipe, and the subsequent subsidence of the soil. Another data reveals a cave-in incident at a site in Fukuoka, Japan, where a massive ground cave-in around a tunnel developed due to leakage of groundwater into the tunnel.

Nevertheless, previous empirical studies have revealed that specialists' surveys to establish the cause of the increasing road cave-ins are scarce. In the event of a sinkhole incident on the road, the concerned emergency response efforts only focus on restoring the utilities, safeguarding public safety, and minimizing public inconvenience (Tang, 2017. The factors causing the sinkholes, such as the nature of soil particles, the availability of degraded underground sewer pipes, the cave-in geometry, or the pipe defect size, are left unexploited. Tang (2017) produced a database summary outlining some of the cave-in incidents caused by soil subsidence due to defective underground sewer pipes, summarized in Table 2.1. 
TABLE 2.1: A SUMMARY OF ROAD CAVE-INS THAT DEFECTIVE UNDERGROUND SEWER PIPES CAUSED

\begin{tabular}{|c|c|c|c|c|c|c|c|}
\hline \multirow[b]{2}{*}{ Ref } & \multirow[b]{2}{*}{ Time } & \multirow[b]{2}{*}{ Location } & \multirow{2}{*}{$\begin{array}{l}\text { Water } \\
\text { condition }\end{array}$} & \multirow[b]{2}{*}{ Type of soil } & \multirow[b]{2}{*}{ Pipe condition and possible cause } & \multicolumn{2}{|c|}{ Consequence } \\
\hline & & & & & & Sinkhole size & Loss \\
\hline 1 & $06 / 1993$ & Georgia, US & Heavy storm & $\begin{array}{l}\text { Soil and } \\
\text { construction } \\
\text { rubble }\end{array}$ & $\begin{array}{l}\text { A sewer tunnel with a diameter of } 4 \mathrm{~m} \\
\text { failure, soil erosion }\end{array}$ & $\begin{array}{l}20 \mathrm{~m} \text { in diameter, } 10 \\
\mathrm{~m} \text { deep }\end{array}$ & $\begin{array}{l}2 \text { killed by pipe } \\
\text { collapse }\end{array}$ \\
\hline 2 & $09 / 2002$ & Tucson, Arizona & $\cdot$ & $\cdot$ & $\begin{array}{l}\text { A broken old sewer pipe of } 42 \text { " diameter, } \\
\text { which was aging and scheduled for } \\
\text { renovation }\end{array}$ & $\begin{array}{l}2 \text { large sinkholes - } \\
\text { exact dimensions are } \\
\text { not available }\end{array}$ & $\begin{array}{ll}\$ 7.7 \text { million for } \\
\text { emergency } & \\
\text { response } & \text { and } \\
\text { repair } & \end{array}$ \\
\hline 3 & $02 / 2007$ & Guatemala & Heavy storm & $\begin{array}{l}\text { Pumice and } \\
\text { volcanic ash }\end{array}$ & $\begin{array}{l}\text { Overloaded sewer or drainage pipe with a } \\
\text { diameter of } 3.75-4.50 \mathrm{~m}\end{array}$ & $\begin{array}{l}20 \mathrm{~m} \text { in diameter, } 60 \\
\mathrm{~m} \text { in deep }\end{array}$ & 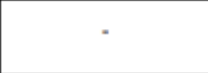 \\
\hline 4 & $09 / 2009$ & Toronto, Canada & Heavy rainfall & $\cdot$ & - & $5 \mathrm{~m}$ wide, $14 \mathrm{~m}$ deep & $\cdot$ \\
\hline 5 & $06 / 2010$ & Guatemala & Heavy storm & $\begin{array}{l}\text { Pumice and } \\
\text { volcanic ash }\end{array}$ & $\begin{array}{l}\text { Overloaded sewer or drainage pipe with a } \\
\text { diameter of } 3.75-4.50 \mathrm{~m}\end{array}$ & $\begin{array}{l}18 \mathrm{~m} \text { in diameter, } 30 \\
\mathrm{~m} \text { deep }\end{array}$ & 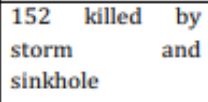 \\
\hline 6 & $09 / 2010$ & Texas, US & $\begin{array}{l}\text { Closer to a } \\
\text { lake }\end{array}$ & Sandy soil & A pipe with a diameter of $1.2 \mathrm{~m}$ failure & $2 \mathrm{~m}$ in diameter & $\cdot$ \\
\hline 7 & $01 / 2011$ & Austin, Texas, US & - & - & Soil erosion into the storm sewer & $2.7 \mathrm{~m}$ deep & - \\
\hline 8 & $02 / 2011$ & Florida, US & $\cdot$ & $\cdot$ & Corroded sewer line & $\begin{array}{l}1.5 \mathrm{~m} \text { in diameter, } 4 \mathrm{~m} \\
\text { deep }\end{array}$ & - \\
\hline 9 & $03 / 2011$ & Ohio, US & Heavy rainfall & $\cdot$ & $\begin{array}{l}\text { A defective } 60 \text {-year-old sewer pipe, the } \\
\text { soil was washed away }\end{array}$ & $\cdot$ & - \\
\hline 10 & $03 / 2011$ & Connecticut, US & - & - & A broken sewer line & $5 \mathrm{~m}$ deep & - \\
\hline
\end{tabular}

Obtained from (Tang 2017)

\subsection{FACTORS CONTRIBUTING TO THE FORMATION OF DETECTIVE SEWER PIPES}

The primary role of the sewer system is the improvement of the environment by safely ferrying away the sewage from the point of generation to the treatment plant. Also, another role of the sewer system is to prevent the creation of vector breeding zones by stagnant sewages and prevent cross-contamination of freshwater sources through seepage of the sewage. Therefore, stringent efforts have been directed towards mitigation of the sewer impact on groundwater quality by preventing the simultaneous influx of sewer water into the sewer pipes and exfiltration of sewage through the sewer pipes into the soil water vicinity sewer lines. A complete sewerage system consists of property sewers, private sewers, sewer pipes, inspection and maintenance holes, overflow structures, sewage pumping stations, vent shafts, and odor-scrubbing systems (Ana et al., 2009). Ana et al. (2009) argued that some sewers consist of a standard piping network ferrying sewage and stormwater.

Several factors are leading to the damage of the sewer pipes. First and foremost, the sewer pipes are subjected to forces of ground movement from natural causes such as earthquakes, leading to defects in the pipes. A study conducted by Malek Mohammadi et al. (2020) established that defects in the sewer pipes could also be caused by individual pipe factors such as aging and deterioration during their period of service. In the long run, leakages and erosion voids created around the pipe cause breakage of the pipes, as the soil supporting the pipes is eroded. Also, the 
voids created around the pipes may cause the ground above the pipes to cave in, creating sinkholes.

Another research conducted by Chang and Zhang (2013) to investigate factors contributing to the structural deterioration of sewer pipes established that poor workmanship causes defects in the underground sewer pipes. For example, gaps and openings left at the pipe joints resulting from poor workmanship can lead to a crack or opening in the pipe. The same study also deduced that using circular cutting wheels when positioning the pipes leads to weakening of the pipes, subjecting the pipe to structural defects (Chang and Zhang, 2013) Another survey carried out by Kuwano (2013) on the critical influences of structural defects in underground sewer pipes in three cities, Nigata, Yokosuka, and Sendai established that inadequate construction works, disruption of pipes by other works and natural deterioration majorly caused the 387 sinkholes discovered in the three cities. According to the survey, inadequate construction was the primary cause of defects in the pipes, representing 30\% (Kuwano, 2013). Furthermore, another study investigating the cause-effect relationship between the sewer material used and the pipe defects established that the chloride-vinyl pipes had a lower percentage of defects than ceramic pipes (Kuliczkowska, 2015). Therefore, sewer pipes made of ceramic materials are highly susceptible to defects.

\subsection{PROBABLE OUTCOMES OF SOIL EROSION DUE TO DEFECTIVE SEWER PIPE}

In recent years, significant interest has developed in modeling and assessing the probable effects of soil erosion resulting from defective sewer pipes. Hoffmans (2014) referred to piping erosion as a deterioration phenomenon that destroys flood defenses by tempering with their structural stability in the event of a flood. There is a wealth of empirical literature providing evidence of the outcomes of underground soil erosion to flood defenses, for example. According to empirical evidence provided by research carried out by Aguilar-López, Warmink, Schielen, and Hulscher (2018), piping erosion has been noted as one of the primary causes of failed flood defenses. The findings of this study proved that any defects on a sewer pipe embedded under a flood defense system could compromise its structural stability and safety in the event of a flood (Aguilar-López et al., 2018). Notably, the weight of the effect is majorly dependent on the characteristics of the sewer pipes, such as the size and location (Aguilar-López et al., 2018). However, predicting this failure mechanism has proved difficult as the failure of the flood defenses can be caused during a flood event. Another study by Hoffmans (2014) concluded that complex underground flood defenses could help tame the likelihood of piping erosion.

Another study established that underground soil erosion due to sewer pipe defects impacts the physical and mechanical characteristics of the soil. According to empirical research conducted by Hewage and Renuka (2012), the loss of soil particles around the sewer pipe destroys the soil structure, resulting in increased porosity and hydraulic conductivity, negatively impacting the shear strength and performance of the ground in the process. Another study of underground soil erosion due to sewer pipe defects and vane shear strengths measured at separate locations along the sewer pipes by Vandenboer, van Beek and Bezuijen (2014) exposed a significant loss in strength the soil immediately adjacent to pipe with the defects. Furthermore, Zhou, Jie, and Li (2012) carried out a series of model tests on the mechanical properties of the fine sand around 
defective underground sewer pipes. According to the results, a cavity is formed in the vicinity of the defective sewer pipes making the soil around the pipe lose. Thus, the soil around the hole was of lower strength than the soil far away from the hole. Hewage and Renuka (2012) further conducted a triaxial test using X-ray CT images on the mechanical properties of the loose sand around a defective sewer pipe. The findings of the study that the stiffness properties of the eroded test sample were almost half that of the original soil specimen (Hewage \& Renuka, 2012). Furthermore, the results revealed that the soils near the cavity located closer to the shear bands were less stiff than those from the cavity located less close to the shear bands (Hewage $\&$ Renuka, 2012). In summary, all the experiments and studies highlighted herein points to the effect of underground soil erosion due to defective sewer pipes on the mechanical properties of the ground.

\subsection{EMBEDMENT MATERIALS}

Previous empirical studies have proved that factors such as sewer pipe embedment materials and particle size of the soil surrounding the pipe influence the erosion around a defective sewer pipe. First, it is prudent to understand that sewer line trenches are backfilled in two zones: the embedment zone and trench fill. Indiketiya, Jegatheesan, Rajeev, and Kuwano (2019) defined the embedment zone as the zone immediately around the pipe, including the haunch support overlay zone, side supports, and the bedding. Often, the embedment zone is backfilled with separate as bedding and embedding (Indiketiya et al., 2019). Therefore, this section looked at the effect of the embedment material on the internal soil erosion due to defective sewer pipes. A primary focus was given to bedding, soil properties, soil type, particle size distribution, initial density, and relative compaction.

\subsubsection{TYPE OF BEDDING}

Some of the critical factors to consider when addressing embedment materials regarding internal soil erosion due to defective sewer pipes are the type and depth of the bedding. According to a study carried out by Khudhair, Basim, and Al-Baidhanic (2021), the kind of bedding was established as one of the factors that determine the susceptibility of the soil to underground erosion in the vicinity of a defective underground sewer pipe. Kaddoura and Zayed (2017) argued that the extent to which the eroded soil migrates is dependent on the type of bedding employed around the sewer pipe. The widely used bedding materials for backfilling around the sewer pipes involve single-size aggregates of between $10-14 \mathrm{~mm}$ as bedding materials. Using uniform-sized, granular materials as bedding materials allows more effortless water movement within the bedding, which in turn washes away the fine particles out of the backfill surrounding the sewer pipe (Kaddoura and Zayed, 2017). Therefore, geotextile is applied to the bedding material to help minimize the migration of fine particles from the backfill surrounding the sewer pipe into the bedding zone.

Another study by Hadjmeliani (2015) comparing the mechanism of soil erosion when different types of sewer pipe beddings are used established that only a limited quantity of loose soil around the defective sewer pipe was lost with class-F bedding (flatbed) while massive settlement of fine particles in the bedding zone was established with the use of Class-S (when granular 
materials surround the sewer pipe) bedding. As a result, it can be deduced that Class-F bedding is recommended for use as bedding materials around the sewer pipe to minimize migration of the soil around a defective sewer pipe. Most importantly, it is worth noting that different countries have varied standards of bedding types. Thus is paramount to assess the risk of erosion regarding the type of bedding employed independently.

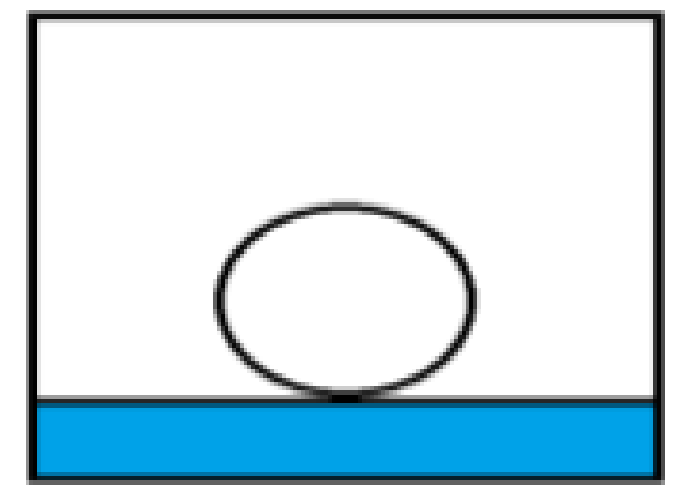

Class - F

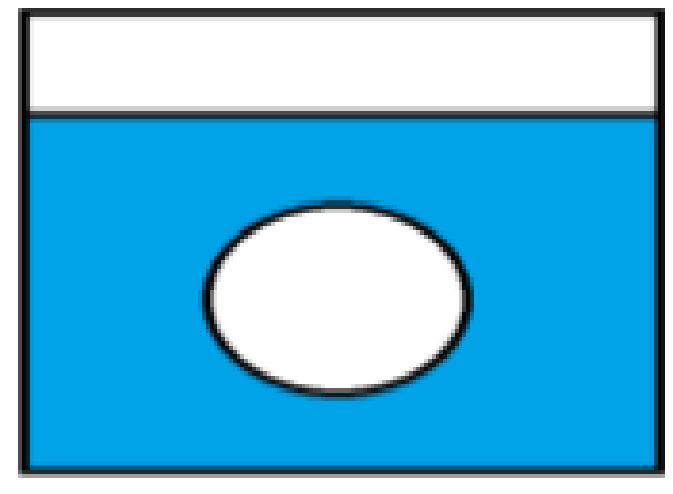

Class - S

FIG 2.5.2.1 BEDDING TYPES.

Obtained from (Hadjmeliani, 2015)

\subsubsection{SOIL PROPERTIES}

Previous empirical studies have proved that soil properties such as soil density, soil type, particle size distribution, and compaction degree affect soil erosion due to defective underground sewer pipes. High relative density (more than $80 \%$ ) will reduce the collapse of the soil around the sewer pipe due to the cyclic nature of water inflow and soil drainage (Mukunoki, Kumano \& Otani, 2012). In their analysis of the failure mechanism of the soil surrounding a defective pipe using single defective analyzing X-ray CT scans, Mukunoki, Kumano, and Otani (2012) established that a low relative density of less than 60 percent relative density has a high collapse rate. Therefore, soils with a low relative density are susceptible to being washed away into the defective pipe, creating cavities around the pipe, causing sinkholes ultimately. The occurrence and propagation of underground erosion largely depend on the surrounding soil's ability to hold the roof or the sides of an already eroded cavity created around a defective pipe under certain conditions. Empirical research conducted by Guo et al. (2013) established that clay soil with high plasticity has the highest degree of resistance to piping erosion, scouring, and holding a cavity roof. The study further deduced that poorly graded, cohesionless fine soil bears the lowest resistance to protecting the top and the sides of the void created due to erosion and can easily cave-in, creating a sinkhole (Guo et al., 2013).

\subsubsection{SOIL TYPE}

Variation of soil types affects the subsidence of the soil around and on top of a defective underground sewer type. According to a study carried out by Khudhair, Nile, and Al-Baidhani 
(2020), clay soil has the highest subsidence by approximately 3.5 times higher than sand soil which is lesser than loam soil by approximately 1.28 times. Khudhair, Nile, and Al-Baidhani (2020) explained that the phenomenon results from the saturated clay soil's shear strength and structural failure losses. Even though clay soil is more prone to subsidence than the other types of soils around a defective sewer pipe, it is least affected by variation in the water pressure. Another study established that sand soil has the higher accumulative properties when eroded while the clay is the least accumulated (Guo \& Zhu, 2017).

\subsubsection{PARTICLE SIZE DISTRIBUTION}

PSD in a particular soil profile significantly affects its susceptibility to erosion and deposition. An investigation of soil movement under cyclic water flow by Helal (2019) established that poorly graded sand soil backfilled around the defective sewer pipe was greatly eroded, creating a more enormous void than uniform fine sand soil when subjected to an equal number of drainage cycles. Another study by Guo and Zhu (2017) investigate the soil flow rate through a defective sewer pipe using three types of non-cohesive sand soil recorded a lower average flow rate with the finer sand, which lasted longer. Also, in the same study, Guo and Zhu (2017) established that the diameter and volume of the cavity created as a result were greater in fine sand than in medium and coarse sand since the finer sand possesses a smaller submerged angle of repose. Furthermore, Helal (2019) examined the filter's effectiveness in holding the crack to prevent the rate of erosion continuation in dams. The findings established that soils that had more remarkable plasticity of fines above $15 \%$ could hold the roof in the progression stage of erosion, thus, slowing down the whole erosion process. In addition, PSD also affects the internal stability of the soil, a vital factor in controlling the soil volumes lost during erosion. An empirical experiment by Helal (2019) proposed that soil with a gap-graded soil of F less than $10 \%$ is more internally stable.

\subsubsection{INITIAL DENSITY AND RELATIVE COMPACTION}

While investigating the impact of density on internal soil influx through defective sewer pipes, Mukunoki et al. (2009) adopted course silica sands of relative densities between 60 and 80 percent. The study's findings established that coarse sand with a lower relative density equaling $60 \%$ formed a void around the defective pipe faster than coarse sand with a higher relative density (Mukunoki et al., 2009). Another study established the level of compaction that affects erosion progression. An experiment carried out by Tsutsumi et al. (2010) on the effect of compaction level on soil erosion progression recorded that the likelihood of holding cracked soil together due to influx of soil into a broken sewer pipe was greater in properly compacted soil during backfilling than poorly compacted soil. The results show that proper compaction of backfilling soil delays erosion progression in embankment filters. 


\subsection{SEWER PIPE DEFECT SIZE}

Defects of an aging sewer pipe allow groundwater infiltration and the water surrounding soil into the pipe. Various analytical studies have highlighted factors such as the sewer pipe defect size, the void ratio, the soil particulate size, and the soil type as critical influencers of groundwater and soil that enter the pipe through the cracks. This section reviewed the effect of the defect size on the sewer pipe on the underground soil erosion. A significant focus was accorded to the granular flow through an opening and sewer pipe defect size measurement using PIV.

\subsubsection{GRANULAR FLOW THROUGH AN OPENING}

To begin with, granular flow through a defect pipe orifice does not depend on the granular height. Various associations have been put forward to estimate the granular flow rate through a defect pipe opening when subjected to different conditions. An empirical study by Sheldon and Durian (2010) investigating the flow rate of granular matter through an opening with an inclination angle proved that there is exists a correlation between the flow rate of the granular matter and the cosine of the inclination angle of an orifice. Furthermore, the shape of the granular particle also affects the ability of soil infiltration into a defective sewer pipe through an opening or crack on the pipe. Sheldon and Durian (2010) experimented on the flow rate of different granular matter with varied shapes. The findings established that the material characteristics of the granular had no significance on the void formation.

In contrast, the shape of the granular particle significantly affected the void formation Sheldon and Durian (2010). Both Beverloo's correlation proposes by several empirical studies and other modified correlations have proved their ability to accurately forecast the granular flow rate of particles through the pipe orifice under different conditions. However, theoretical analysis is paramount to establish the mechanism of granular flow rate through an opening in the pipe.

\subsubsection{SEWER PIPE DEFECT SIZE MEASUREMENT USING PIV}

Particle Image Velocimetry (PIV) is a velocity measurement parameter that utilizes imaging correlation. The PIV procedures majorly consist of three significant steps; image pre-processing, image evaluation, and post-processing (Muste et al., 2014). According to Muste et al. (2014), Pre-processing the images before proceeding to conduct the analysis enhances the quality of the images, thus improving the accuracy of the correlation. A PIV analysis was performed for pipe defect size concerning sand velocity distribution. From the sand velocity distribution curves obtained for various defect positions, the downward sand velocity is continuously decreased as the defect position is shifted from bottom to top of the defect sewer pipe (Kong et al., 2017). Also, the same experiment established as the defect changes from the top to assume a horizontal position, the width of the mobilized zone increases a little (Kong et al., 2017).

\subsection{PRINCIPLES AND METHODOLOGY}

The study utilized a qualitative study design. The methodology utilized was the review of secondary data from 3 specific studies. The selected study must be conducted within the past two years. Studies selected were not country-specific since there is a significant similarity in erosions across the world due to defective sewers. The studies should also be published since published 
studies have higher credibility. The selected studies were also not limited to specific methodologies. The review included only those studies that researched defect size, particle size, and embedment material. Indiketiya, Jegatheesan, Rajeev and Kuwano, (2019) were selected since it was conducted within the past two years. It is also a study that was done to meet Australian standards. Khudhair, Basim and Al-Baidhani, (2021) and Hameed, Al-Baidhani and Basim, (2020) were also included since they met all the set criteria.

The study involved secondary analysis of both qualitative and quantitative data. Therefore, the research carried out the critical interpretive analysis, examining 3 quantitative studies mention above published in the last two years from the current year of study, 2021. The themes, purpose, context, and methodologies employed in the selected research articles were critically synthesized. The chapter described the material selection and the traits of the tools used to collect data towards achieving the study aims and objectives of the research. As discussed in Chapter 2, it was prudent to analyze secondary data on the factors that cause internal soil erosion due to defective sewer pipes.

\subsection{QUALITATIVE SECONDARY DATA ANALYSIS}

A concrete definition of secondary data analysis regarding qualitative data is not yet to be coined: however, qualitative analysis of secondary data can be defined as the synthesis of qualitative research data by a single removed from the process with the aim of either expounding on the original findings, tackling different questions that were otherwise not addressed in the original paper, or employing other methods to address the initial research questions (Ruggiano \& Perry, 2019). Several qualitative secondary data analysis typologies include analytic expansion, retrospective interpretation, armchair induction, and meta-Ethnography (Ruggiano \& Perry, 2019). In this research, the secondary data analysis for the selected three literary works was analyzed using the meta-ethnography typology. According to Johnston (2019), metaethnography involves a comparative textual analysis of published research experiments through translating qualitative studies into one another, avoiding the aggregation of researchers trying to create generalizations and general conclusions in the process (Johnston, 2019). Figure 3.1.1 illustrates the process that was adopted to synthesize the secondary data for the selected themes.

The synthesis begins with secondary analysis. The secondary analysis involves analyzing existing qualitative databases with a view of examing the literature, answering initial study questions with different methods, or otherwise addressing new questions (Largan \& Morris, 2019). The following procedure will be meta-analysis which involved analyzing the findings from multiple data sources to address original questions (Largan \& Morris, 2019). The last procedure was a collaboration involving interactions between the researcher and the policymakers outside the study context. 


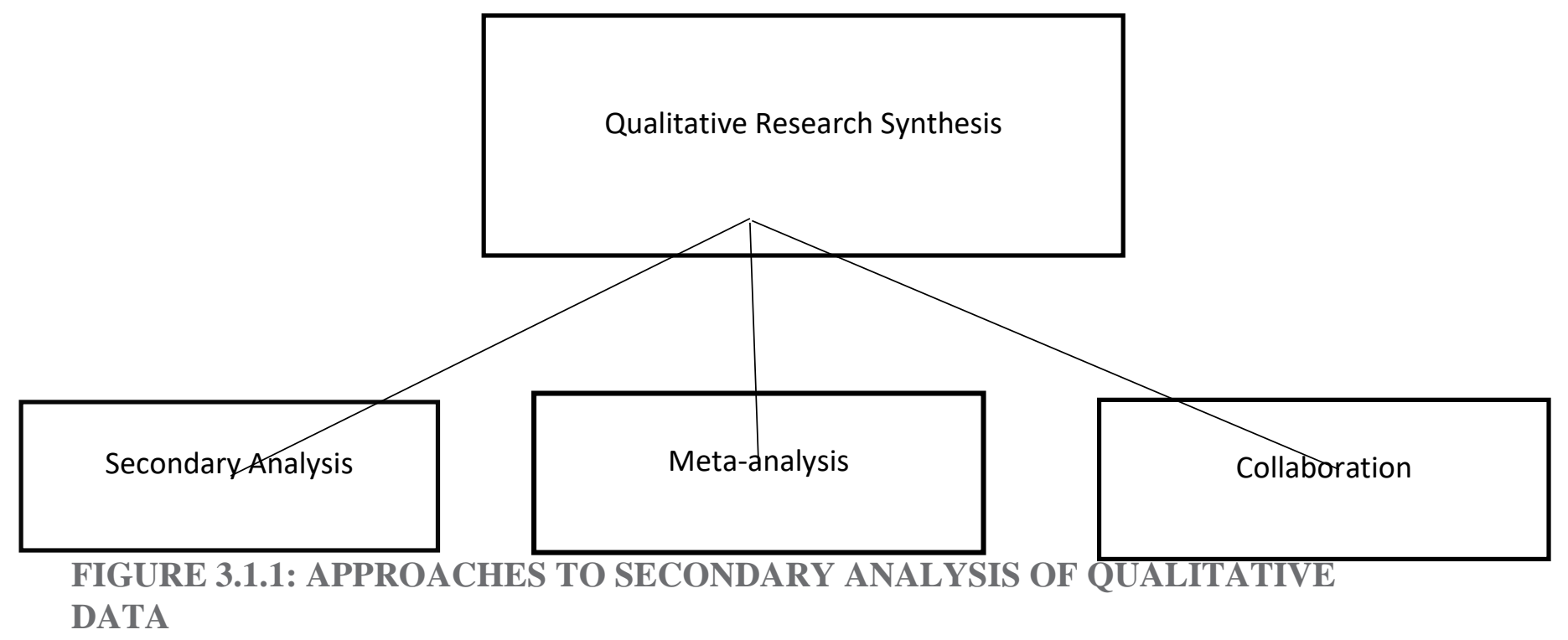

\subsection{ELIGIBILITY CRITERIA}

The meta-ethnography approach assed published peer-reviewed and scholarly journals between the years 2019 and 2021. In the process, it was prudent to meet the inclusion criteria as outlined in this section. First, data that was obtained using qualitative research tools were analyzed. Another step was subjecting the parent research data analysis to subsequent analysis. Finally, the findings of the analysis were shared in English. Furthermore, unpublished dissertations were excluded from the final data analysis due to the limited time that the research was conducted.

\subsection{SOURCES AND THE PROCESS OF DATA SEARCH}

The three studies were identified between the years 2019 and 2021 by searching from online databases. The databases searched included Social Work Abstracts, EBSCO Host, Expanded Academic ASAP, and Web of Science. For the four online database platforms used, a search was initiated using the following search words; qualitative research OR qualitative analysis AND two studies OR two field studies. Out of the studies searched, 10 unduplicated pieces of research were highlighted to be subjected to further synthesis. Among the 10 articles subjected to complete analysis, only 3 met the inclusion criteria, while 7 were excluded from the ultimate analysis.

\subsection{APPRAISAL OF STUDIES}

Given that the current research focused on the findings of the selected studies for particular topics, the appraisal of the parent studies was inclined towards the description and comparisons of the findings in three phases. Phase 1 focused on the literature search from Scientific Databases $(n=10)$. Phase 2 involved appraisal of unduplicated studies $(n=10)$, while Phase 3 detailed parent studies of literary papers that Met Eligibility Criteria and Inclined in Analysis $(n=3)$. The study will involve searching the relationship between the study and the original study. The associations will be identified by authors-citing the parent study and the authors' researchers outlining their intention for the data obtained from the parent study. Another category involved 
the context of SDA. In this docket, the assessment revealed whether the secondary analysis aimed to advance a particular theory. Secondary data was analyzed based on whether the whole datasets had been analyzed in the SDA or whether new study questions had been deployed, different from the parent study. Also, the systematic review of data sort establishes details about the original study. Here, the research establishing the context within which data for the original research for each selected article was obtained, assessing the selected studies on whether they incorporated details about the original study and the mechanism of sharing the findings.

\subsection{RIGOR IN SECONDARY DATA ANALYSIS}

The two most significant concerns with Secondary Data Analysis (SDA) are rigor and ethics. Some researchers have raised concerns over potential ethical problems, particularly regarding sharing the secondary data and when SDA is carried out by researchers not involved in the original data collection (Forero et a;., 2018). One significant advantage of adopting SDA is to reduce the burden of identifying, accessing, and recruiting study participants (Tripathy, 2013). However, significant rigor and ethical concerns come to the publication of secondary qualitative research findings. As argued by Tripathy (2013), a qualitative study involves collecting and interpreting data based on the social, cultural, and political constructs at the time of data collection. There are several approaches for increasing rigor in qualitative secondary data analysis. For the present study, we carried out audit trials and critical and reflective constant comparisons. However, Forero et al. (2018) argued that this model does not eliminate the bias that comes with inappropriate coding and interpretation of data by the secondary data researchers. Therefore, to achieve credibility of the findings, the study adopted the FourDimensions Criteria (FDC) method to achieve rigor. FDC primarily involved establishing the credibility, dependability, confirmability, and transferability of the findings from secondary data analysis (Forero et al., 2018).

\subsection{ETHICAL CONSIDERATIONS}

Besides issues with the medthodological rigor in secondary data analysis, criticism has also been thrown at the ethical dilemmas created by the SDA approaches. The ethical concerns for SDA revolve around issues of consent, the anonymity of sharing such data, and confidentiality. According to Tripathy (2013), qualitative data results from a collaboration between the researcher and the respondents. Therefore, allowing such that to be re-used by secondary researchers creates ethical and legal dilemmas concerning the respondent's possession of the original data (Tripathy, 2013). Also, the risk of breaches of confidentiality and anonymity of respondents in reviewing secondary qualitative data is realized with researchers who share personal information with the respondents in the effort to build a good rapport with them. In the present study, ethical dilemmas were addressed by ensuring the consent of study subjects before proceeding with data synthesis. Also, confidentiality and anonymity of the participants of the parent study were ensured by not re-identifying them in the data analysis. 


\subsection{STUDY RESULTS}

\subsection{EFFECTS OF THE SIZE OF DEFECT OF SEWER PIPE ON SOIL EROSION}

Well-graded crushed rock with a Dmax of $9.5 \mathrm{~mm}$ was highly resistive even through $30 \mathrm{~mm}$ wide openings (Indiketiya, Jegatheesan, Rajeev \& Kuwano, 2019). In another study, Khudhair, Basim, and Al-Baidhani, (2021) found that using tiny gravel as a protective bedding layer has significant benefits, including reducing erosion and cavity formation by $95.4 \%$.

\subsection{EFFECT OF EMBEDMENT MATERIAL ON SOIL EROSION BY DEFECTIVE SEWER PIPES}

Indiketiya, Jegatheesan, Rajeev and Kuwano, (2019) found that poorly-graded sand with Dmax of $4.75 \mathrm{~mm}$ was highly vulnerable to erosion through $10 \mathrm{~mm}$ wide cracks regardless of the fines particles proportion and the level of gradation. The goal was to ensure the material utilized as embedment highly course regardless of their size. Course material is known to have a high level of compactness and can significantly reduce erosion. Specifically, their edges are rough, and they can hold on together regardless of defect size. To increase the accuracy of these results, sixteen tests on two groups, i.e., those with a protective layer and those without, were conducted. Gravel is known to have high compactness, and the area also highly resistant to erosion. Using such material in the bedding of pipes greatly influences reducing erosion and increasing internal strength. Hameed, Al-Baidhani, and Basim (2020) evaluated various soils to establish their subsidence rate. The study established that clay soil suffers more from subsidence than erosion. Clay soil can effortlessly cement, and thus it is not easily washed away. However, if they can be fluidized, the result will likely be subsidence of the above soil.

According to Khudhair, Basim, and Al-Baidhani, (2021), granular media is commonly used as embedment materials around the sewer pipes. Such granular matter have often had an impact on erosion of soils around the pipes as well as subsidence of the soil on the roof of the pipes. A study conducted by Khudhair, Basim, and Al-Baidhani, (2021), to investigate the effectiveness of tiny granular matter in protecting the top of sewer pipes established that small gravel media largely impacted the cumulative erosion soil weight and the overall creation of a void around the pipe as illustrated in figure 4.2.1. According to the findings in figure 4.2.1, the volume of eroded mass decrease 18.25 times for a single crevice when a tiny gravel layer was used. Similar results were obtained when tiny gravel was used for multi-defective cases. In this experiment, no voids were formed both with multiple or single crevice on the sewer pipe when tiny gravel was used. Therefore, it can be inferred from the results that tiny gravel most likely offers effective protection as embedment material through preventing the soil matter around the pipe from being sucked into the pipe and eroded away. 


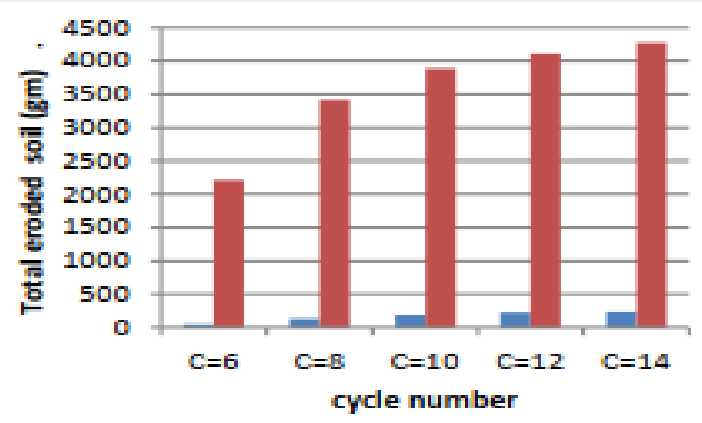

- Accumaltive Eroded Soil Mass (gm) with gravel for single crack

- Accumaltive Eroded Soil Mass (gm) without gravel for single crack

FIGURE 4.2.1 CUMULATIVE ERODED MASS WITH AND WITHOUT GRAVEL LAYER IN VARIOUS TEST CYCLES.

Obtained from (Khudhair, Basim, and Al-Baidhani, 2021).

\subsection{EFFECT OF SOIL CHARACTERISTICS ON SOIL EROSION DUE TO DEFECTIVE SEWER PIPES}

Hameed, Al-Baidhani, and Basim (2020) valuate various soil types to establish the impact of the ration between the physical characteristics of such as soil density and permeability to that of water pressure ( $\ell . \mathrm{K} 2 / \mathrm{P})$ in the defective pipe on the total amount of the soil eroded. Their findings were plotted as illustrated in figure 4.31 . According to the figures plotted in figure 4.3.1, Hameed, Al-Baidhani, and Basim (2020), deduced that the variations in the water pressure inside the defective sewer pipe affects the soil erosion mechanisms, in which cavities around the pipe will form at a faster rate with the sandy soil that has the same permeability and relative density. A comparison with another similar study by Karpf, Traenckner, and Krebs (2009) investigating a similar study question established these properties of the soil affect the hydraulic modelling of the sewage exfiltration. 


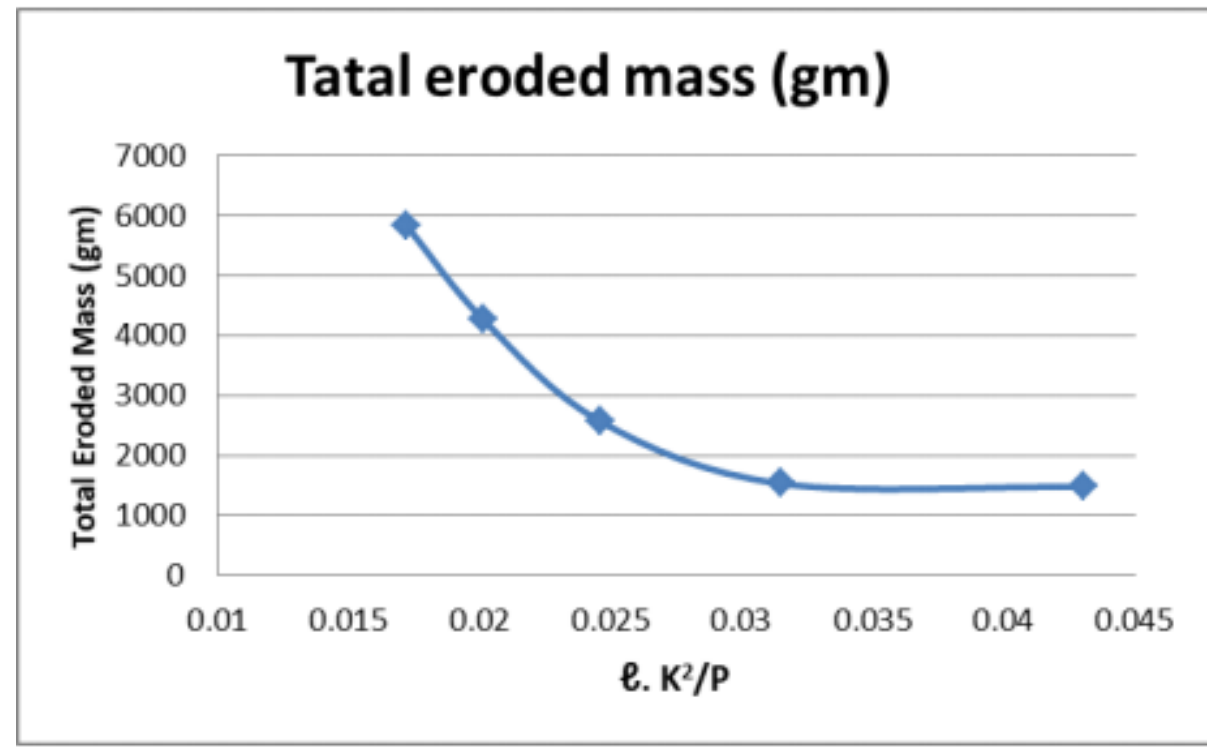

FIGURE 4.3.1: RELATIONSHIP OF THE TOTAL ERODED MASS OF LOCAL SANDY SOIL TYPES WITH WATER PRESSURE.

Obtained from (Hameed, Al-Baidhani \& Basim, 2020).

\subsection{CONCLUSIONS AND RECOMMENDATIONS}

\subsection{CONCLUSIONS}

The primary objective of the study was to investigate the mechanisms of underground soil erosion due to defective sewer pipes. The key conclusions from the study are summarized in point form as per the study questions of the research as follows:

From the reviewed methodology of the experiments conducted in the reviewed original studies, the PIV analysis was effectively employed to examine the failure mechanism of the erosion of the soil around a defective pipe.

Regarding the influence of the size of the defect in the pipe on the magnitude of internal soil erosion, the study established a significant potential for a massive soil influx into the defect pipe with poorly-graded soils when the crevice on the defective pipe was is greater the Dmax or 2D85 of the soil around the defect hole. Similar results also indicated that erosion of the soil is negligible when B is smaller than the Dmax.

More so, the results proved that hole creation around the defect pipe was faster when the pipe defect size was larger.

More so, the study deduced that the geometry of the erosion around the defective pipe and the formation of a cavity was dependent on other several factors including the B/Dmax ration, magnitude of leakage, the depth of the ground surface from the pipe defect and the type of soil. 
Conclusions regarding the effect of embedment materials on erosion and sinkhole formation due to defective sewer pipe stablished the resistance to erosion for well-graded crushed rock with a Dmax of $9.5 \mathrm{~mm}$ was higher as compared to that of the Dromana sand which has a lower Dmax of $5 \mathrm{~mm}$.

Based on the analysis of the secondary data included in the study, internal soil erosion due to defective sewer pipes mitigation will be highly achieved if the embedment materials have a higher Dmax or D85 values that using non-cohesive embedment materials.

Furthermore, migration of soil 10-30 mm holes on the defective pipe rarely occurs when the soil in the vicinity of the pipe is well-graded, and has some traces of medium gravel, so long as the soil is properly compacted to exceed 80 percent of its relative density.

In addition to the findings of the results, a comparison of 3 gradations of Type 361 soils revealed that finer embedment materials leads to faster formation of voids around the defective pipe and slowed expansion of the voids then a course graded soil with the same Dmax.

\subsection{RECOMMENDATIONS}

The findings and approach of the present study presents an opportunity for future study to further explore the research questions. Even the results from the secondary analysis of data producing desirable outcomes in achieving the specific objectives of the studies, there were some limitations, which can be improved in future similar research works. First and foremost, further studies are recommended to reduce the skin friction, while improving the accuracy of the PIV technique. Since some of the limitations from the grading curves of sewer pipe defective materials have potential to minimize sinkholes caused by underground soil erosion due to defective pipes, there is need to modify the current standard. Additionally, the experiments that were used by researchers in the original studies only focused on the pipe defects around the crown of underground pipes. Hence, it is recommended that future studies their examination so different sewer pipe defect orientations. Finally, the literature review showed a gap in the number of studies that have been conducted to examine the impact of rainfall on the stability of underground cavities formed around defective pipes. Therefore, it would be prudent for future studies to examine the effect of rainfall induced groundwater rise and downward infiltration of rainwater on the cave-in of the already existing underground cavities around a defective sewer pipe. 


\section{References}

Aguilar-López, J. P., Warmink, J. J., Schielen, R. M. J., \& Hulscher, S. J. (2018). Piping erosion safety assessment of flood defences founded over sewer pipes. European journal of environmental and civil engineering, 22(6), 707-735.

Ana, E., Bauwens, W., Pessemier, M., Thoeye, C., Smolders, S., Boonen, I., \& De Gueldre, G. (2009). An investigation of the factors influencing sewer structural deterioration. Urban Water Journal, 6(4), 303-312.

Chang, D.S., and Zhang, L.M. (2013). Extended internal stability criteria for soils under seepage. Soils and Foundations 53(4): 569-583. doi: http://dx.doi.org/10.1016/j.sandf.2013.06.008.

Forero, R., Nahidi, S., De Costa, J., Mohsin, M., Fitzgerald, G., Gibson, N., ... \& Aboagye-Sarfo, P. (2018). Application of four-dimension criteria to assess rigour of qualitative research in emergency medicine. BMC health services research, 18(1), 1-11.

Guo, S., Shao, Y., Zhang, T., Zhu, D. Z., \& Zhang, Y. (2013). Physical Modelling on Sand Erosion around Defective Sewer Pipes under the Influence of Groundwater. Journal of Hydraulic Engineering, 139(12), 1247-1257.

Guo, S., \& Zhu, D. Z. (2017). Soil and groundwater erosion rates into a sewer pipe crack. Journal of Hydraulic Engineering, 143(7), 06017008.

Hadjmeliani, M. (2015). Degradation of sewage pipe caused Sinkhole: A real case study in a main Road. In Congrès français de mécanique. AFM, Association Française de Mécanique.

Helal, E. (2019). Experimental evaluation of changes in channel bed morphology due to a defective pressure flow pipe. Journal of Irrigation and Drainage Engineering, 145(10), 04019022.

Hewage, I., \& Renuka, S. (2012). Evaluation of ground loosening behavior and mechanical properties of loosened sand associated with underground cavities.

Hoffmans, G. J. C. M. (2014, November). An overview of piping models. In Proceedings of the 7th International Conference on Scour and Erosion (pp. 3-18). CRC Press.

Indiketiya, S., Jegatheesan, P., \& Rajeev, P. (2017). Evaluation of defective sewer pipe-induced internal erosion and associated ground deformation using laboratory model test. Canadian Geotechnical Journal, 54(8), 1184-1195.

Indiketiya, S., Jegatheesan, P., Rajeev, P., \& Kuwano, R. (2019). The influence of pipe embedment material on sinkhole formation due to erosion around defective sewers. Transportation Geotechnics, 19, 110-125.

Johnston, M. P. (2017). Secondary data analysis: A method of which the time has come. Qualitative and quantitative methods in libraries, 3(3), 619-626.

Jo, Y. S., Cho, S. H., \& Jang, Y. S. (2016). Field investigation and analysis of ground sinking development in a metropolitan city, Seoul, Korea. Environmental Earth Sciences, 75(20), 1-19. 
Kaddoura, K., and Zayed, T. (2017). Erosion Void Prediction Model for Sewer Pipelines. In International Congress on Underground Infrastructure, Water Management and Trenchless Technology, Istanbul. pp. 114-126.

Karoui, T., Jeong, S. Y., Jeong, Y. H., \& Kim, D. S. (2018). Experimental study of ground subsidence mechanism caused by sewer pipe cracks. Applied Sciences, 8(5), 679.

Karpf, C., and Krebs, P. (2011). Quantification of groundwater infiltration and surface water inflows in urban sewer networks based on a multiple model approach. Water Research 45(10): 3129-3136. doi: http://dx.doi.org/10.1016/j.watres.2011.03.022.

Karpf, C., Traenckner, J., \& Krebs, P. (2009). Hydraulic modelling of sewage exfiltration. Water Science and Technology, 59(8), 1559-1565.

Khudhair, H. H., Basim, K. N., \& Al-Baidhani, J. H. (2021, February). Experimental study of the effect on soil erosion of using tiny gravel as bedding for defective sewer pipes. In IOP Conference Series: Materials Science and Engineering (Vol. 1067, No. 1, p. 012008). IOP Publishing.

Khudhair, H. H., Nile, B. K., \& Al-Baidhani, J. H. (2020). Evaluation the Effect of Pressure Head and Soil Type on Erosion and Subsidence of Soil Due to Defective Sewers. Kerbala Journal for Engineering Science, 1(1), 1-12.

Kong, B., Li, Z., Yang, Y., Liu, Z., \& Yan, D. (2017). A review on the mechanism, risk evaluation, and prevention of coal spontaneous combustion in China. Environmental Science and Pollution Research, 24(30), 23453-23470.

Kuliczkowska, E. (2015). Analysis of defects with a proposal of the method of establishing structural failure probability categories for concrete sewers. Archives of Civil and Mechanical Engineering, 15(4), 1078-1084.

Kuwano, S. (2013). TUESDAY MORNING, 4 JUNE 2013 517D, 7: 55 AM TO 8: 40 AM Session 2aID. J. Acoust. Soc. Am, 133(5 Pt 2).

Largan, C., \& Morris, T. (2019). Qualitative secondary research: A step-by-step guide. Sage.

Malek Mohammadi, M., Najafi, M., Kermanshachi, S., Kaushal, V., \& Serajiantehrani, R. (2020). Factors Influencing the Condition of Sewer Pipes: State-of-the-Art Review. Journal of Pipeline Systems Engineering and Practice, 11(4), 03120002.

Mukunoki, T., Kumano, N., \& Otani, J. (2012). Image Analysis of Soil Failure on Defective Underground Pipe due to Cyclic Supply and Drainage Using X-ray CT. Frontiers of Structural and Civil Engineering, 6(2), 85-100.

Mukunoki, T., Kumano, N., Otani, J., \& Kuwano, R. (2009). Visualization of three dimensional failure in sand due to water inflow and soil drainage from defective underground pipe using Xray CT. Soils and Foundations, 49(6), 959-968. 
Muste, M., Hauet, A., Fujita, I., Legout, C., \& Ho, H. C. (2014). Capabilities of large-scale particle image velocimetry to characterize shallow free-surface flows. Advances in water resources, 70, 160-171.

Ruggiano, N., \& Perry, T. E. (2019). Conducting secondary analysis of qualitative data: Should we, can we, and how?. Qualitative Social Work, 18(1), 81-97.

Sheldon, H. G., and Durian, D. J. (2010). "Granular discharge and clogging for tilted hoppers." Granular

Matter, 12(6), 579-585

Tang, Y. 2017. Mechanisms of Soil Erosion due to Defective Sewer Pipes. Ph.D. Thesis, Department of Civil and Environmental Engineering, University of Alberta

Tang, Y., Zhu David, Z., and Chan Dave, H. 2017. Experimental Study on Submerged Sand Erosion through a Slot on a Defective Pipe. Journal of Hydraulic Engineering 143(9): 04017026. doi: 10.1061/(ASCE)HY.1943-7900.0001326.

Tripathy, J. P. (2013). Secondary data analysis: Ethical issues and challenges. Iranian journal of public health, 42(12), 1478.

Vandenboer, K., van Beek, V., \& Bezuijen, A. (2014). 3D finite element method (FEM) simulation of groundwater flow during backward erosion piping. Frontiers of Structural and Civil Engineering, 8(2), 160-166.

Yokota, T., Fukatani, W., Toyohisa, M., and Takeuchi, D. (2017). Analysis of abnormalities in sewer pipes contributing to stock management. Wastewater System Division, Water Quality Department, National Institute for Land and Infrastructure Management. Japan.

Zhou, X. J., Jie, Y. X., \& Li, G. X. (2012). Numerical simulation of the developing course of piping. Computers and Geotechnics, 44, 104-108. 